https://doi.org/10.15407/ujpe63.5.413

T. GAVRILKO,${ }^{1}$ I. GNATYUK,${ }^{1}$ V. STYOPKIN,${ }^{1}$ N. SHCHERBAN,${ }^{2}$ J. BARAN,${ }^{3}$ M. DROZD ${ }^{3}$

${ }^{1}$ Institute of Physics, Nat. Acad. of Sci. of Ukraine

(46, Prosp. Nauky, Kyiv 03028, Ukraine)

${ }^{2}$ L.V. Pisarzhevsky Institute of Physical Chemistry

(31, Nauki Ave., Kyiv 03028, Ukraine)

${ }^{3}$ Institute of Low Temperature and Structure Research, PAS

(2, Okolna Str., 50-422, Wroclaw, Poland)

\title{
FTIR AND DSC STUDIES OF BINARY MIXTURES OF LONG-CHAIN ALIPHATIC COMPOUNDS: LAURIC ACID - CETYLTRIMETHYLAMMONIUM BROMIDE ${ }^{1}$
}

\begin{abstract}
Structural and thermal properties of a solid-state binary mixture of long-chain cationic and anionic surfactants (so-called catanionic complexes) composed of cetyltrimethylammonium bromide, $\left[\mathrm{H}_{3} \mathrm{C}-\left(\mathrm{CH}_{2}\right)_{15}-\mathrm{N}^{+}\left(\mathrm{CH}_{3}\right)_{3} \mathrm{Brr}^{-}(\mathrm{CTAB})\right.$, and saturated fatty acid (FA), $\mathrm{CH}_{3}\left(\mathrm{CH}_{2}\right)_{12} \mathrm{COOH}$ (lauric acid, kC12), are studied. To clarify the effect of intermolecular interactions on the crystalline structure and phase transitions in this class of supramolecular compounds, the 1:1 kC12-CTAB binary mixture is investigated by means of X-ray diffraction, differential scanning calorimetry (DSC), and temperature-variable Fourier transform infrared spectroscopy (FTIR). Based on the comparison of the obtained results with those of other $C T A B-F A$ binary mixtures with different alkyl chain length mismatches, the possible molecular packing in the crystal phase of CTAB-FA complexes and the mechanism of successive phase transitions in the condensed state are proposed.
\end{abstract}

Keywords: catanionic complexes, lauric acid, CTAB, DSC, FTIR.

\section{Introduction}

Mixtures of oppositely charged long-chain cationic and anionic surfactants (so-called catanionic complexes, CA) are a subject of great interest both from practical and theoretical points of view. During the past decades, CA are attracting much interest both from fundamental (crystal engineering and supramolecular development) and applied points of view due to their remarkable ability to form bilayers and vesicles instead of micelles in the bulk phase, fast adsorption kinetics, and very low surface tension [1-4]. The CA compounds are of great applica-

(C) T. GAVRILKO, I. GNATYUK, V. STYOPKIN, N. SHCHERBAN, J. BARAN, M. DROZD, 2018 tion potential as lubricants and detergents in industry and technology, as well as for various encapsulation and controlled delivery processes in pharmacy, medicine, and biology. The fundamental understanding of these systems is required for different industrial and daily applications such as food stuff, detergents, cosmetics, or pharmaceutical and petroleum industry. The electrostatic interaction between oppositely charged head groups results in the formation of ionic pairs forming compounds similar to those of double-tail surfactants [5-6]. Due to a wide range of

1 The paper was presented at the XXIII Galyna Puchkovska International School-Seminar "Spectroscopy of Molecules and Crystals". 
microstructures that could be fabricated by adjusting the composition and packing parameters, these systems are recently also used for the delivery of drugs and the synthesis of nano- and mesomaterials [7-9]. The range of different structures observed in these systems reflects the intermolecular interaction; especially, the balance of the electrostatic interactions between oppositely charged head groups and the hydrophobic interactions between alkyl tails. The theoretical interest in these systems is focused on the variety of behaviors that the mixtures can show, as compared to their separate components. So far, the studies of the temperature-dependent transitions of long-chain molecular structures were mainly focused on ternary water systems, while the thermotropic properties of binary catanionic complexes in the solid state are still not completely understood. Differential scanning calorimetry (DSC) and FTIR spectroscopy show that the CA compounds demonstrate a rich complex thermotropic behavior, with the alkyl chain length mismatch of components in some cases having a significant effect on the phase behavior. Several liquid crystalline phases appear between the solid crystalline phase and the isotropic liquid phase [10, 11]. Many aspects of the CA structure and phase behavior in the solid state have still to be clarified. Recently, we investigated the structural and thermal properties of solid-state binary mixtures of long-chain cationic and anionic surfactants composed of cetyltrimethyl-ammonium bromide, $\left[\mathrm{H}_{3} \mathrm{C}-\right.$ $\left.\left(\mathrm{CH}_{2}\right)_{15}-\mathrm{N}^{+}\left(\mathrm{CH}_{3}\right)_{3}\right] \mathrm{Br}^{-}(\mathrm{CTAB})$, and saturated fatty acids (FA), $\mathrm{CH}_{3}\left(\mathrm{CH}_{2}\right)_{n} \mathrm{COOH}$, where $n$ is the number of carbon atoms in the alkyl chain, with longer alkyl chains containing an even number of carbon atoms $n$ and differing from that of CTAB by two (stearic acid, $n=18, \mathrm{kC18}$ ) and four ( $n=22$, behenic acid, kC22) carbon atoms. The obtained results revealed the influence of the alkyl chain length mismatch between the components of a binary mixture on the thermophysical properties of the obtained supramolecular compound. We also studied the effect of the molar fraction of components on the phase behavior of binary mixtures consisting of CTAB and $\mathrm{kC18}$. In [12-13], we reported the results obtained on the binary mixtures of CTAB and saturated normal fatty acids with longer alkyl chains containing an even number of carbon atoms and differing from that of CTAB by two $(\mathrm{kC18})$, and four $(\mathrm{kC} 22)$ carbon atoms and revealed the influence of the alkyl chain mismatch on the thermal properties of the catanionic surfactant. As an extension of this work, we have also investigated the phase behavior of binary mixtures with various compositions composed of CTAB and $\mathrm{kC} 18$ fatty acid. We demonstrated that a simple change of the concentrations of components significantly affects thermotropic properties of the binary mixture [13]. However, the thermotropic properties of binary catanionic complexes in the solid state still have a lot of open questions. In particular, the role of alkyl chain length on the molecular packing pattern in the CA crystals and the nature of molecular interactions in this class of supramolecular compounds need to be studied in detail.

In this work, we devoted particular attention to solid-state complexes of CTAB and lauric acid ( $\mathrm{kC12})$ with shorter alkyl chain. Lauric acid is an inexpensive, non-toxic, and well-investigated compound. It is solid at room temperature with melting point about $45{ }^{\circ} \mathrm{C}$. The crystals of lauric acid A-form, which was used in our experiments, were studied by $\mathrm{X}$ ray diffraction, and the $\mathrm{A}$ polymorph of $\mathrm{kC12}$ crystals was identified as belonging to the triclinic symmetry, spatial group P1 with six molecules per unit cell [14]. Therefore, unlike the other previously studied CA complexes composed of CTAB and FA and having the same orthorhombic crystal symmetry, the $\mathrm{kC} 12$ crystal structure is incommensurate with that of CTAB. This was our another motivation for the selection of the $\mathrm{kC} 12$ compound as an anionic counterpart in the CTAB-kC12 binary mixture with the hope to evaluate the possible effect of the initial crystal symmetry of the components on the structure and molecular interactions of the resulting supramolecular compound.

The crystal structure and solid-liquid phase behavior of the $1: 1 \mathrm{kC} 12$-CTAB binary mixture were investigated by means of X-ray diffraction, differential scanning calorimetry (DSC), and temperature-variable Fourier transform infrared spectroscopy (FTIR). The obtained results are compared with those of other CTAB-FA binary mixtures with longer alkyl chain acids, stearic $(\mathrm{kC1} 18)$ and behenic $(\mathrm{kC} 22)$. Within the series, the headgroups of the cationic and anionic counterpart remains constant; while, for the anionic counterpart, its alkyl chain length varies from 12 to 22 carbon atoms. By systematically varying the length of the alkyl radical of the CA complex, we get better insight on the structure of the catanio-

ISSN 2071-0194. Ukr. J. Phys. 2018. Vol. 63, No. 5 
nic complex itself and, in particular, the head group bonding features.

\section{Experimental}

\subsection{Materials and samples preparation}

The initial compounds, CTAB (Fluka, 99\%) and lauric ( $\mathrm{kC12}$ ) acid (Sigma-Aldrich), were used without purification. The 1:1 kC12-CTAB binary complex (hereinafter, referred as "the complex") was prepared according to the procedure previously described elsewhere [12]. First, pristine kC12 powder was dissolved in bi-distilled ethanol under a warm condition at $40{ }^{\circ} \mathrm{C}$ at a concentration of about $3 \%$ wt. Then an equal molar amount of previously dried CTAB powder was added to the solution. The reagent mixture was kept at the elevated temperature for a half of one hour to ensure that the reaction between the components takes place. The formation of a new supramolecular compound after the reaction was evident from visual changes of the solution appearance, which became slightly opalescent unlike the transparent initial solution. The obtained reaction mixture was cooled slowly to room temperature. After the complete ethanol evaporation, the reaction product was extracted as a solid white precipitate, dried, and stored in a desiccator. The weight of the obtained samples was usually in the range $5-10 \mathrm{mg}$. The reaction scheme and molecular structure of the initial compounds and the obtained complex are shown in Fig. 1.

\subsection{Experimental methods}

The crystal structures of the obtained solid complex, as well its initial components, $\mathrm{kC} 12$ and $\mathrm{CTAB}$, were studied by small-angle X-ray powder diffraction. The XRD patterns were obtained at room temperature with a 139 DRON-3M Xray diffractometer, by using $\mathrm{Cu}_{K \alpha}$ radiation filtered with a $\mathrm{Ni}$ foil.

The thermophysical characteristics of the complex were measured in the $20-130{ }^{\circ} \mathrm{C}$ temperature interval with a Perkin-Elmer Model 8000 differential scanning calorimeter (DSC) for a sample weight of 3.5$6 \mathrm{mg}$ at a cooling/heating rate of $8{ }^{\circ} \mathrm{C} / \mathrm{min}$. A standard indium sample served for a calibration of the enthalpy values. For comparison, the DSC curves for the initial compounds ( $\mathrm{kC1}$ and $\mathrm{CTAB}$ ) were also measured. The phase transition parameters, transition temperatures, and changes in enthalpy were derived from DSC data with built-in computer software.

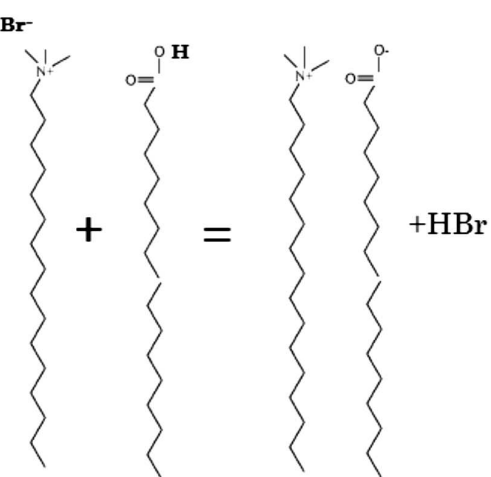

Fig. 1. Molecular structures of CTAB lauric acid $(\mathrm{kC12})$ and the $1: 1 \mathrm{kC} 12-\mathrm{CTAB}$ binary complex

The temperature-variable FTIR transmission spectra (400-4000 $\mathrm{cm}^{-1}$ spectral range) of the investigated complex, as well as those of initial $\mathrm{kC12}$ and CTAB, were measured with a Bruker IFS-88 FTIR spectrometer in a $20-150{ }^{\circ} \mathrm{C}$ temperature interval with a resolution of $1 \mathrm{~cm}^{-1}$ and a wavelength definition accuracy better than $0.01 \mathrm{~cm}^{-1}$. The measurements repeatability was $0.5 \mathrm{~cm}^{-1}$ by frequency and about 0.0005 by absorbance. The SPECAC Variable Temperature Cell P/N 21.500 and Automatic Temperature Controller P/N 20,120 Series supplied with Eurotherm controller 847 were used for the measurements. Deconvolution and decomposition of the spectral bands were performed using the Origin-6.0 software package. Peak positions of the absorption bands were defined, by using the second derivative method and/or the standard data processing procedure. The $\mathrm{kC} 12$ and $\mathrm{kC12-CTAB}$ samples for FTIR spectra measurements were sandwiched between $\mathrm{KBr}$ windows, while the CTAB sample was prepared, by using the $\mathrm{KBr}$ pellets technique.

\section{Results and Discussion}

\subsection{X-ray diffraction}

XRD patterns of the investigated compounds are shown in Fig. 2. The analysis of the obtained XRD data reveals that, like initial $\mathrm{kC} 12$ and $\mathrm{CTAB}$ compounds, the resulted complex exhibits a well-ordered layered crystalline structure showing the strong reflection maximum at about 2.136 degrees. A similar crystal structure was previously reported in our earlier paper for crystalline $1: 1 \mathrm{kC} 18-\mathrm{CTAB}$ and $\mathrm{kC} 22$ CTAB complexes [12]. The reflections from the initial compounds are not further observed in the XRD pat- 


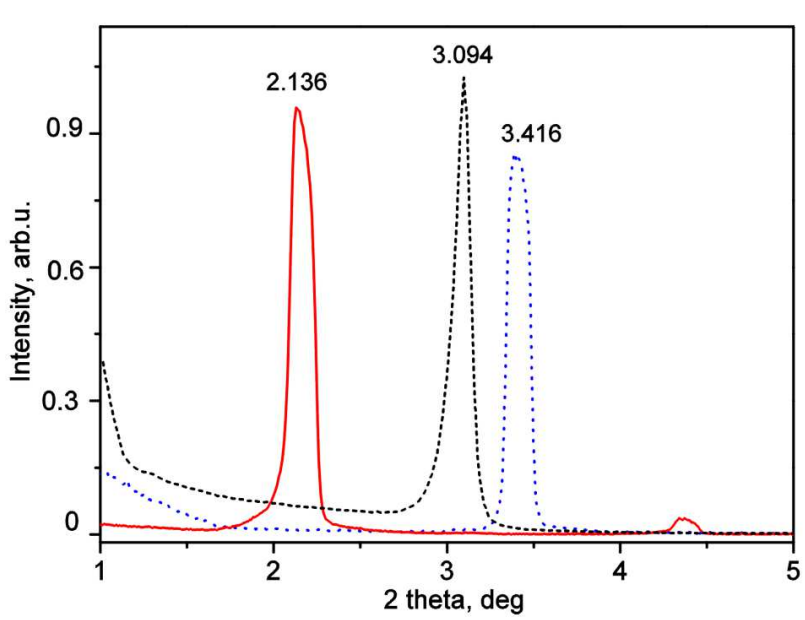

Fig. 2. Room temperature small-angle X-ray powder diffraction patterns from the $1: 1 \mathrm{kC12-CTAB}$ binary complex (solid line) and its initial components, CTAB (dotted line) and $\mathrm{kC12}$ (dashed line)

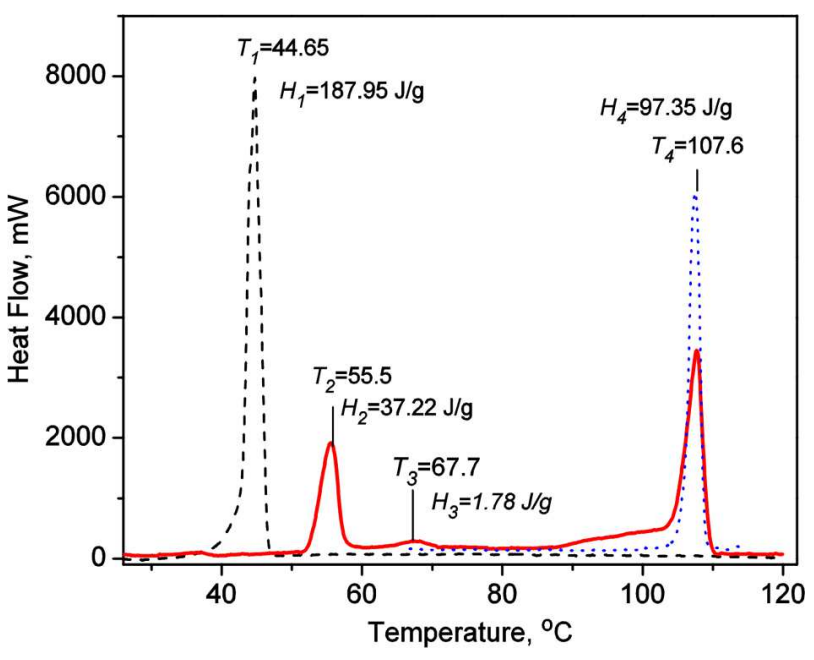

Fig. 3. Thermograms of the $1: 1 \mathrm{kC} 12-\mathrm{CTAB}$ binary complex (solid line) and initial components: $\mathrm{kC12}$ (dashed line) and CTAB (dotted line) in the heating run. The " $H$ " value represents the enthalpy change for the corresponding phase transition

tern from the complex (Fig. 2), which confirmed that the obtained compound is not just a physical mixture of the components, but represents a new crystalline structure. According to the XRD results, the basic lamellar spacing for the $\mathrm{kC12-CTAB}$ crystal structure is $4.58 \mathrm{~nm}$, meaning that fully extended alkyl chains in the complex are closely packed and assembled into molecular bilayers similar to that of $1: 1 \mathrm{kC} 18$-CTAB and $\mathrm{kC} 22-\mathrm{CTAB}$ complexes. Starting from this interlayer distance, it is possible to calculate a tilt angle for the alkyl chains in the complex as equal to $70.6^{\circ}$.

Though X-ray diffraction shows the lamellar structure of the complex, this technique cannot give the particular molecular arrangement of molecular moieties in the bilayers, e.g. their local positions relative to one another, as well as the mutual orientation of their head groups and alkyl chains. Using FTIR spectroscopy, it is possible to solve this problem as could be seen below.

\subsection{Differential scanning calorimetry}

DSC curves of the $\mathrm{kC12-CTAB}$ complex are shown in Fig. 3. The obtained DSC values (the phase transition temperature, $T$, and the enthalpy change, $H$ ) are similar to those reported in [15-17] for other long-chain compounds. The analysis of DSC data shows that the thermothropic behavior of the prepared $\mathrm{kC} 12-\mathrm{CTAB}$ complex is very different from that of initial components. Contrary to the initial $\mathrm{kC} 12$ with one sharp endothermic peak at the melting point of $T_{1}=44.65{ }^{\circ} \mathrm{C}$ and the initial CTAB with one peak at $T_{4}=107.6{ }^{\circ} \mathrm{C}$, the $\mathrm{kC12-CTAB}$ binary complex shows a set of successive phase transitions in the temperature range between the acid melting and CTAB solid-state transition temperatures. On heating, three endothermic transitions are observed for the $\mathrm{kC12-CTAB}$ binary complex prior to its melting at $109^{\circ} \mathrm{C}$ : the most pronounced one at $T_{2}=55.5^{\circ} \mathrm{C}$ and two additional transitions with smaller enthalpies with onset at $T_{3}=67$ and $T_{4}=98{ }^{\circ} \mathrm{C}$. The temperatures of these transitions do not coincide with any of the transition points observed for the constituting components, which indicates that the obtained reaction product is not a physical mixture of the initial components, but a new supramolecular compound. For the initial crystalline CTAB, it was shown [18] that, at $T=103{ }^{\circ} \mathrm{C}$, it undergoes an endothermic solid-solid phase transition, which results in the melting of the nonpolar bilayers, while the ionic layers remain practically unaffected. CTAB is also known to decompose at $250{ }^{\circ} \mathrm{C}$ without melting, which is explained by strong ionic interactions in polar layers [18]. The electrostatic interactions between the head groups in the ionic layers are much stronger than the van der Waals forces between the hydrocarbon chains. It is the ionic binding 
forces that are responsible for the enhanced melting temperature of this crystal. The CTAB melting temperature is so high that its thermal decomposition occurs prior to the melting. The successive phase transitions that are observed for the complex are very common in the long-chain aliphatic compounds due to their alkyl chain conformational flexibility and related polymorphism. Judging from the corresponding enthalpy changes shown in Fig. 3 and the comparison with corresponding values for particular phase transitions in similar compounds, the transitions observed in the complex could be described as solidsolid crystalline, solid crystalline-liquid crystalline, and liquid crystalline-isotropic liquid. From the comparison with the thermograms previously obtained on other FA-CTAB binary complexes, $\mathrm{kC18-CTAB}$ and $\mathrm{kC22-CTAB} \mathrm{[12],} \mathrm{it} \mathrm{is} \mathrm{obvious} \mathrm{that} \mathrm{the} \mathrm{number} \mathrm{of}$ phase transitions in these compounds do not depend on the difference between the alkyl chain lengths of CTAB and FA. In addition, as the difference between the alkyl chain lengths increases, the solid phases are seen to be more stable, whereas the mesophase stability interval is expanding for the complexes with closer chain lengths.

The changes observed in thermotropic properties of the complexes with different alkyl chain length mismatches suggest different molecular interactions in these compounds due to different charge distributions of the spatial head group, as well as different molecular bilayer packing densities.

Finally, our thermal analysis of the binary mixtures of $\mathrm{kC12}$ and $\mathrm{CTAB}$ confirmed the formation of a supramolecular complex with a number of phase transitions and a melting point different from that of pure $\mathrm{kC} 12$ and CTAB. However, the DSC measurements do not give unambiguously the type of the occurring transition and the precise phase identification, especially for the phase transitions with small enthalpy changes. Below, we will try to get a deeper insight into the nature of the observed phase transitions with the help of variable-temperature FTIR spectroscopy.

\subsection{FTIR spectroscopy}

The molecular structure of the complex and the nature of the observed successive thermotropic phase transitions were investigated by FTIR spectroscopy. The formation of a supramolecular compound was confirmed with FTIR spectroscopy by frequency shifts and the partial or total disappearance of characteristic vibrations of $\mathrm{kC} 12$ and $\mathrm{CTAB}$. The IR-active bands in the FTIR transmission spectra of the studied compounds were identified with the help of previously published results on fatty acids or similar molecular compounds [19, 20]. From IR spectroscopic observations, the temperature-induced changes in the alkyl chain conformation and molecular packing at the solid-state phase transitions of the binary complex were defined after the detailed study of the spectral parameters of characteristic IR absorption bands.

\subsubsection{Alkyl chain $\mathrm{CH}_{2}$ stretching vibrations and conformational ordering of hydrocarbon tails of the kC12-CTAB complex}

The alkyl chain conformation in different phases of the complex can be derived from the position of symmetric and asymmetric $\mathrm{CH}_{2}$ stretching bands. It is known that the frequency of $\mathrm{CH}_{2}$ asymmetric stretching vibrations of the alkyl tail decreases with the conformational ordering in the hydrocarbon chain [21]. The $\mathrm{C}-\mathrm{H}$ stretching vibrations of the alkyl chain are sensitive to the conformation of methylene chains. For example, when the $\mathrm{CH}$ asymmetric stretching $\nu_{s}\left(\mathrm{CH}_{2}\right)$ band is positioned lower than $2852 \mathrm{~cm}^{-1}$, this indicates of a more ordered crystalline structure, while its higher values are representative of disordered crystal phases and liquid crystals [22]. Therefore, $\mathrm{CH}_{2}$ stretching vibrations are used as a reference for the conformational order of a methylene hydrocarbon chain of long-chain aliphatic compounds. The fragment of the variable-temperature FTIR spectra for the complex in the $\mathrm{C}-\mathrm{H}$ stretching region is shown in Fig. 4, a. The asymmetric and symmetric $\mathrm{CH}_{2}$ stretching vibrational frequencies, $\nu_{\text {as }}\left(\mathrm{CH}_{2}\right)$ and $\nu_{s}\left(\mathrm{CH}_{2}\right)$, respectively, are observed at 2917 and $2849 \mathrm{~cm}^{-1}$. The asymmetric $\nu_{\text {as }}\left(\mathrm{CH}_{3}\right)$ and symmetric $\nu_{s}\left(\mathrm{CH}_{3}\right) \mathrm{CH}_{3}$ groups stretching vibrations are located at 2955 and $2873 \mathrm{~cm}^{-1}$, respectively, with lower intensities. The $\nu_{\text {as }}\left(\mathrm{CH}_{3}\right)$ position at a frequency lower than $2956 \mathrm{~cm}^{-1}$ is an indicative of the crystalline structure. The $\nu_{\text {as }}\left(\mathrm{CH}_{2}\right)$ stretching band observed at $2917 \mathrm{~cm}^{-1}$ suggests a highly ordered alkyl chain with all-trans $\mathrm{CH}_{2}$ conformation. When the temperature increases, this band shifts from 2917 to higher $2924 \mathrm{~cm}^{-1}$ frequencies, which means that the number of gauche conformers increases, and the number of highly ordered all- 

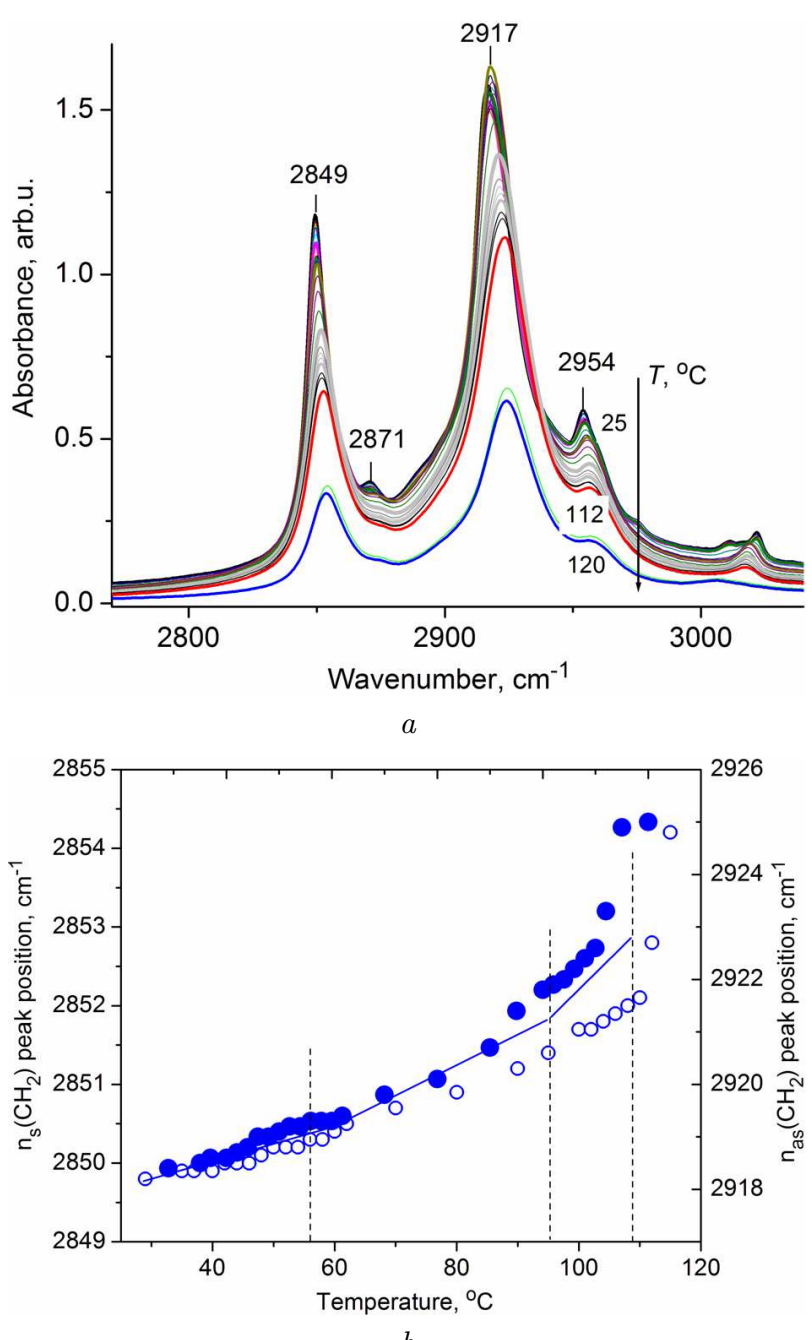

$b$

Fig. 4. Temperature evolution of (a) FTIR spectra of the $1: 1 \mathrm{kC} 12$-CTAB complex in the $\mathrm{CH}$ stretching region, and $(b)$ peak position for $\nu_{s}\left(\mathrm{CH}_{2}\right)$ (open circles) and $\nu_{\text {as }}\left(\mathrm{CH}_{2}\right)$ (filled circles). Solid lines in graph $(b)$ are drawn as a guide for eye

trans conformers of alkyl chain decreases. This behavior corresponds to a change from the ordered crystalline solid phase to a more disordered liquid or liquid crystalline one. Figure $4, b$ presents the temperature dependence of $\nu_{\mathrm{as}}\left(\mathrm{CH}_{2}\right)$ and $\nu_{s}\left(\mathrm{CH}_{2}\right)$ stretching frequencies. Although a gradual increase in this value with the temperature is observed, it is not a linear relationship. It can be clearly seen from Fig. 4, $b$ that, for both $\nu_{\text {as }}\left(\mathrm{CH}_{2}\right)$ and $\nu_{s}\left(\mathrm{CH}_{2}\right)$, there is more than one gradient change between the lower and higher frequency regions, showing that at least two phase transitions are involved in the cor- responding temperature range. The gradient change points fairly well match the transition temperatures observed in DSC thermograms for the $\mathrm{kC12-CTAB}$ complex (Fig. 3). Therefore, we could conclude that the mechanism of the observed phase transitions is related to the alkyl chains disordering and/or melting. However, it is difficult to define the precise nature of the observed phase transitions based only on the $\mathrm{CH}_{2}$ symmetric and asymmetric stretching bands. Therefore, relevant changes in the FTIR spectra in the head group vibrations region need to be considered as well.

\subsubsection{Alkyl chain $\mathrm{CH}_{2}$ rocking vibrations and molecular packing of hydrocarbon tails of the kC12-CTAB complex}

Additional information about the alkyl chains packing could be retrieved from the in-plane $\mathrm{CH}_{2}$ rocking vibrations band, $\delta\left(\mathrm{CH}_{2}\right)$, in the $720-800 \mathrm{~cm}^{-1}$ spectral range. This band is known to be very sensitive to lateral chain interactions and the molecular packing in the condensed state [23]. Another important feature is the observed splitting of the $\delta\left(\mathrm{CH}_{2}\right)$ band into a doublet with two components at $720 \mathrm{~cm}^{-1}$ and $730 \mathrm{~cm}^{-1}$. It is known that the splitting of IR absorption bands into several components with different polarizations (known as the Davydov splitting (DS) of vibrational excitons) appears due to the ordered crystalline environment, and it is generally observed for crystals with several molecules per unit cell. In aliphatic compounds, this splitting is characteristic of the orthorhombic packing of all-trans alkyl chains with two translationally non-equivalent $\mathrm{CH}_{2}$ fragments in Vand's subcell and is absent in the monoclinic and triclinic crystals [23]. It is worth to note that the Davydov splitting value decreases, as the lateral interaction between the alkyl chains decreases [24]. Therefore, the changes in the alkyl chains packing can be defined from the temperature dependence of the Davydov splitting (DS, $\left.\mathrm{cm}^{-1}\right)$ of the $\delta\left(\mathrm{CH}_{2}\right)$ absorption band.

Figure 5 shows the DS temperature dependence of the $\delta\left(\mathrm{CH}_{2}\right)$ mode in the FTIR spectra of the binary complex and the initial compounds $\mathrm{kC12}$ and CTAB. As seen from Fig. 5, in the FTIR spectra of the complex, the $\delta\left(\mathrm{CH}_{2}\right)$ band is centered at $720 \mathrm{~cm}^{-1}$, which is indicative of fully extended methylene chains. The observance of the Davydov split- 
ting of the $\delta\left(\mathrm{CH}_{2}\right)$ band for the complex indicates that the methylene chains of both $\mathrm{kC} 12$ and $\mathrm{CTAB}$ moieties in the crystalline phase of the supramolecular compound are packed in a lamellar structure with two molecules per orthorhombic Vand's subcell. It is worth mentioning that the initial $\mathrm{kC1} 12$ does not display DS in its crystalline phase, since it belongs to a triclinic crystal structure with one molecule per Vand's cell. The room temperature DS value in the initial CTAB $\left(11.5 \mathrm{~cm}^{-1}\right)$ is larger, as compared to its value in the complex $\left(9.5 \mathrm{~cm}^{-1}\right)$ indicating a more loose packing of alkyl chains in the crystalline structure of the binary complex. These different values of DS observed for the complex and CTAB alone agree well with the results of X-ray diffraction. Both for pure CTAB and the complex, the DS value gradually decreases with the temperature, the decrease rate being faster for the complex. The DS value drops to zero at $T=60{ }^{\circ} \mathrm{C}$ and $T=114{ }^{\circ} \mathrm{C}$ for the complex and CTAB, respectively, suggesting that, at these points, a change in the methylene chains packing from the orthorhombic into another crystalline structure occurs. From Fig. 5, a, a drastic broadening of the Davydov splitting components above the solid-solid phase transition temperature is also seen. This indicates that, in the newlyformed phase, the methylene chains are in a dynamically disordered or hindered rotation state and are packed in the so-called hexagonal or rotary phase [25]. Considering that a conformational disorder of alkyl chains is developed at the same temperatures, as defined from the changes in the FTIR spectral parameters of $\mathrm{CH}_{2}$ stretching vibrations (Fig. 4), all these changes indicate a cooperative nature of the observed solid-solid phase transitions in the complex, which includes the temperature-induced alkyl chain "melting" phenomenon in the bilayers followed by the transition in the crystal structure from the orthorhombic to hexagonal phase. Note that the phase transition points defined for the complex from FTIR spectroscopy are close to, but not exactly matching those defined with DSC measurements (Fig. 3). The difference can be attributed to the different temperature gradient distributions over the sample in the DSC (sealed pan) and FTIR (KBr windows sandwich) measurements.

Summarizing, our variable-temperature FTIR spectroscopic measurements suggest that the successive endothermic phase transitions occurring in the com-

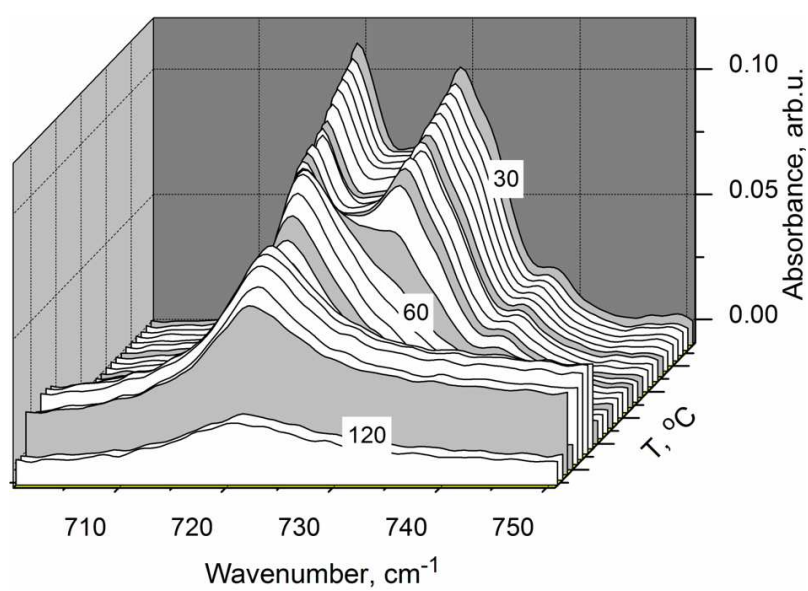

$a$

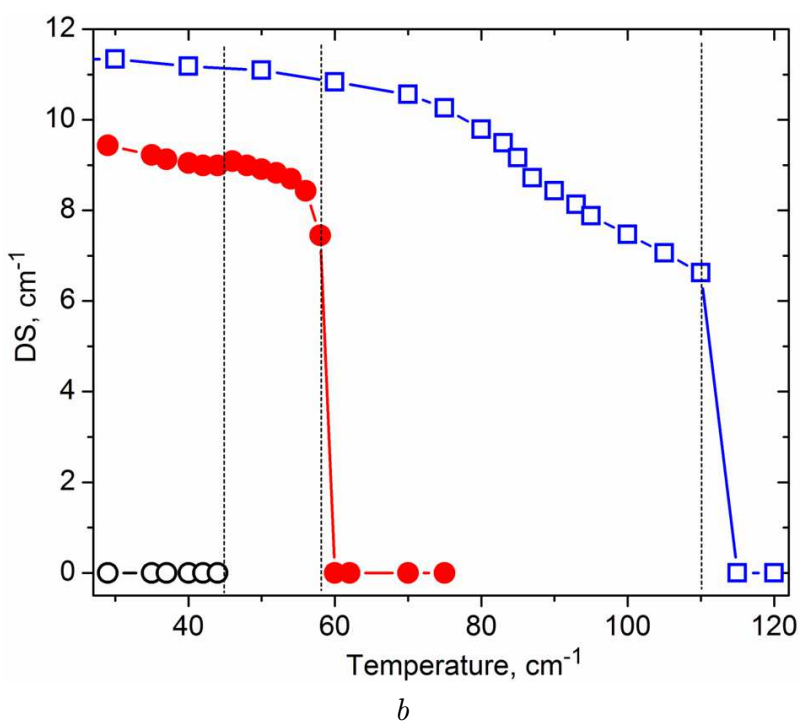

Fig. 5. Temperature dependence of the $\delta\left(\mathrm{CH}_{2}\right)$ rocking mode (a) and the Davydov splitting, DS, $(b)$ in the FTIR spectra of the $1: 1 \mathrm{kC} 12-\mathrm{CTAB}$ binary complex (filled circles) and the initial compounds: $\mathrm{kC} 12$ (open circles), and CTAB (open squares)

plex are connected with a cooperative dynamical disorder in its structure due to the conformational "melting" and hindered molecular rotations of alkyl chains.

\subsubsection{Head group vibrations region}

The existence of binding non-covalent interactions between the $\mathrm{kC} 12$ and $\mathrm{CTAB}$ moieties in the complex could be inferred from the changes in the FTIR spectra in the region of characteristic vibrations of the polar terminal group. There are the $1600-1800 \mathrm{~cm}^{-1}$ 


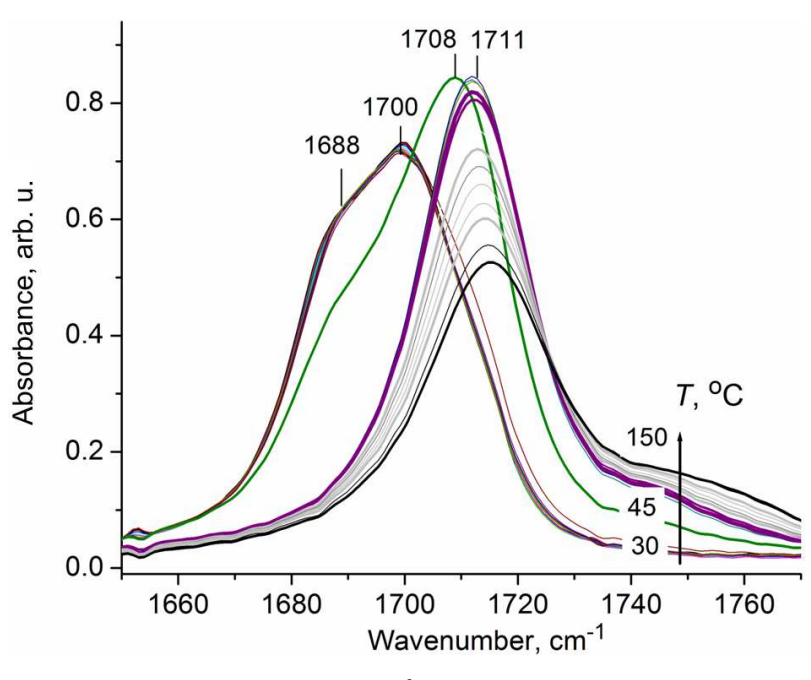

$a$

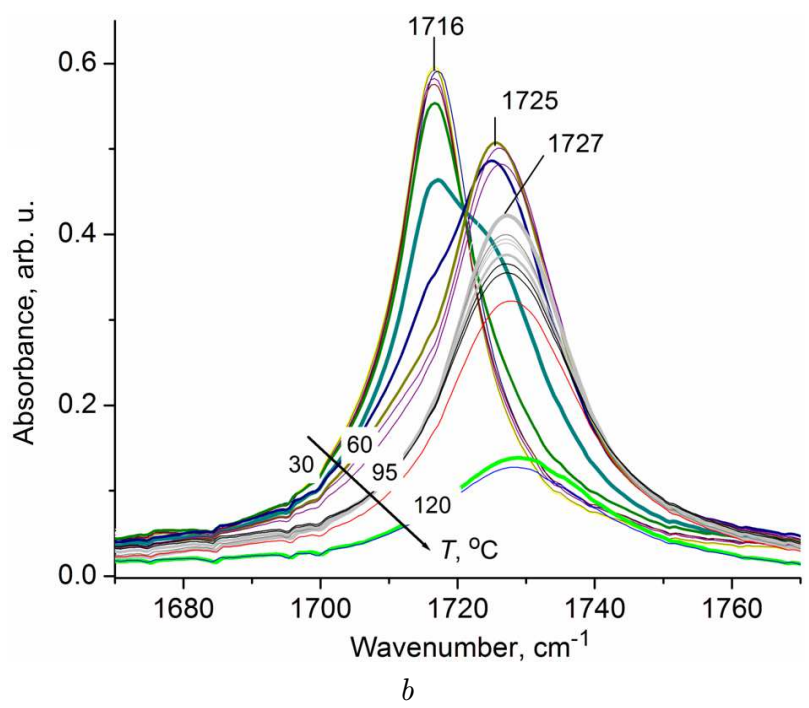

Fig. 6. Temperature evolution of the carbonyl stretching band in the FTIR spectra of pristine $\mathrm{kC12}(a)$ and the $1: 1 \mathrm{kC12}$ CTAB binary complex $(b)$

region of $\nu(\mathrm{C}=\mathrm{O})$ carbonyl stretching vibrations, 900-1000 $\mathrm{cm}^{-1}$ region of $\nu\left(\mathrm{C}-\mathrm{N}^{+}\right)$stretching, and $1400-1500 \mathrm{~cm}^{-1}$ region of $\mathrm{N}^{+}-\left(\mathrm{CH}_{3}\right)_{3}$ bending vibrations. Figure 6 illustrates the temperature-induced changes of the $\nu(\mathrm{C}=\mathrm{O})$ band before and after the $\mathrm{kC} 12$ doping with $\mathrm{CTAB}$. In the room-temperature FTIR spectra of the initial kC12 (Fig. 6, a), the carbonyl stretching band of the crystalline $\mathrm{kC12}$, which occurs in the solid state in a dimeric form, has only one strong band at $1700 \mathrm{~cm}^{-1}$ with a shoulder at about $1688 \mathrm{~cm}^{-1}$ due to $\nu(\mathrm{C}=\mathrm{O})$ vibrations in co-

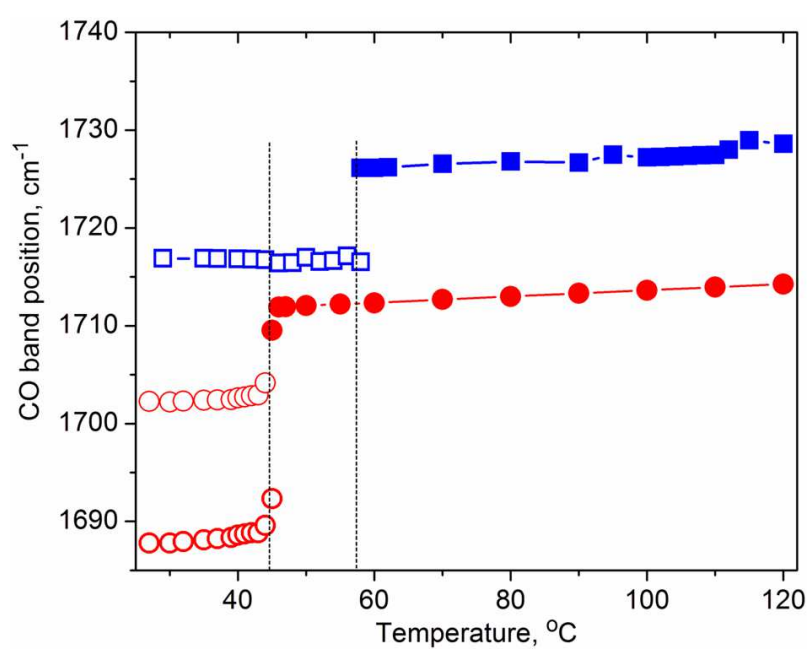

Fig. 7. Temperature evolution of the carbonyl stretching band /components position for the $1: 1 \mathrm{kC} 12$-CTAB binary complex (squares) and pristine $\mathrm{kC1} 2$ (circles)

existing trans- and cis-conformations of hydrogenbonded cyclic dimers. Upon the heating, the conformational equilibrium is shifted in favor of the transform, so the cis-conformer vibration band weakens. Finally, at the melting temperature, the single $\mathrm{C}=\mathrm{O}$ stretching band remains with the peak position shifted to $1712 \mathrm{~cm}^{-1}$. This is due to the fact that, in its crystalline form, the acid molecules are arranged in dimers, but this association is less ordered under the melting, leaving a more electron density in the single $\mathrm{C}=\mathrm{O}$ bond and, therefore, making it stronger. In the FTIR spectra of the complex (Fig. 6, b), the carbonyl stretching band of dimeric acid molecules centered at $1700 \mathrm{~cm}^{-1}$ is not further observed. But a new blue-shifted band is displayed at $1716 \mathrm{~cm}^{-1}$. The $1716 \mathrm{~cm}^{-1}$ band position indicates the presence of a carboxylic carbonyl group that is not hydrogen-bonded, as compared to that in the initial $\mathrm{kC12}$ acid dimers, and is much "free" than $\mathrm{kC12}$ monomers. As can be seen from Fig. 7 illustrating the temperature evolutions of the carbonyl stretching band position for the complex and pristine $\mathrm{kC12}$, the shift to higher frequencies occurs gradually until it reaches the critical temperature, where an abrupt change occurs. These temperatures are about $44{ }^{\circ} \mathrm{C}$ for the pristine $\mathrm{kC} 12$ and $57^{\circ} \mathrm{C}$ for the complex and match well the temperatures of the first solid-solid phase transition obtained for these compounds by DSC. As was shown above, at the same time, the 
conformational "melting" of well-ordered hydrocarbon chains has already occurred, by triggering a transition from the orthorhombic packing of methylene chains to the hexagonal phase. This gives an increase in the distances between the polar $\mathrm{COO}^{-}$and $\mathrm{N}^{+}$ $\left(\mathrm{CH}_{3}\right)_{3}$ groups, which leads to a weakening of the binding interaction and results in a shortwave shift of the $\mathrm{C}=\mathrm{O}$ stretching band. Since both structural changes were observed simultaneously, the gradual increase of the $\mathrm{C}=\mathrm{O}$ stretching frequency seems to be correlated with changes in the alkyl chain packing.

In the prepared supramolecular complex, the $\mathrm{kC} 12$ dimers do not further exist, and the $\mathrm{N}^{+}-\left(\mathrm{CH}_{3}\right)_{3}$ group is located near the carbonyl one instead of that of the second acid dimer in the pristine $\mathrm{kC} 12$. The electrostatic field of $\mathrm{N}^{+}$ion of CTAB is screened partially by its "umbrella" $\mathrm{CH}_{3}$ groups. This leads to increasing the carbonyl stretching force constant and, therefore, to a high-frequency shift of its position. This binding electrostatic interaction together with the hydrophobic interchain interaction govern the formation of a supramolecular complex. The molecular structure of the complex is similar to that of bitail lipids with two alkyl tails from $\mathrm{kC1} 2$ and $\mathrm{CTAB}$ moieties and the bulky head-group comprising electrostatically bind ionized carbonyl group $\mathrm{COO}^{-}$and the trimethylammonium cation $\mathrm{N}^{+}\left(\mathrm{CH}_{3}\right)_{3}$. Meanwhile, some authors consider this interaction as an extreme form of the hydrogen bonding with proton transfer [26]. However, we have no clear explanation at present for this kind of interaction, and it needs a further investigation.

The further support for a modified head-group structure could be obtained from the observed changes in the FTIR spectra in the regions of $\mathrm{C}-$ $\mathrm{N}^{+}$and $\mathrm{N}^{+}-\left(\mathrm{CH}_{3}\right)$ stretching vibrations of the CTAB moiety of the complex. As illustrated by Fig. 8, the vibrational bands of a trimethylammonium cation also change after the binary complex formation. It can be seen from Fig. 8 that the $\mathrm{C}-\mathrm{N}^{+}$stretching (Fig. 8, a) and $\delta_{\text {as }}\left(\mathrm{N}^{+}-\mathrm{CH}_{3}\right)$ (Fig. 8, b) bands in the complex are broaden and shifted to lower frequencies, as compared to that in the initial CTAB. Note that, in Fig. 8, b, the 1480 and $1487 \mathrm{~cm}^{-1}$ bands are assigned to the $\delta_{\text {as }}\left(\mathrm{N}^{+}-\mathrm{CH}_{3}\right)$ stretching mode, and the 1462 and $1472 \mathrm{~cm}^{-1}$ absorption bands are related to the $\rho\left(\mathrm{CH}_{2}\right)$ mode Davydov splitting. Similar to the $\mathrm{CH}_{2}$ rocking mode, the $\delta\left(\mathrm{CH}_{2}\right)$ mode splitting value decreases with the temperature. Finally at the melt-
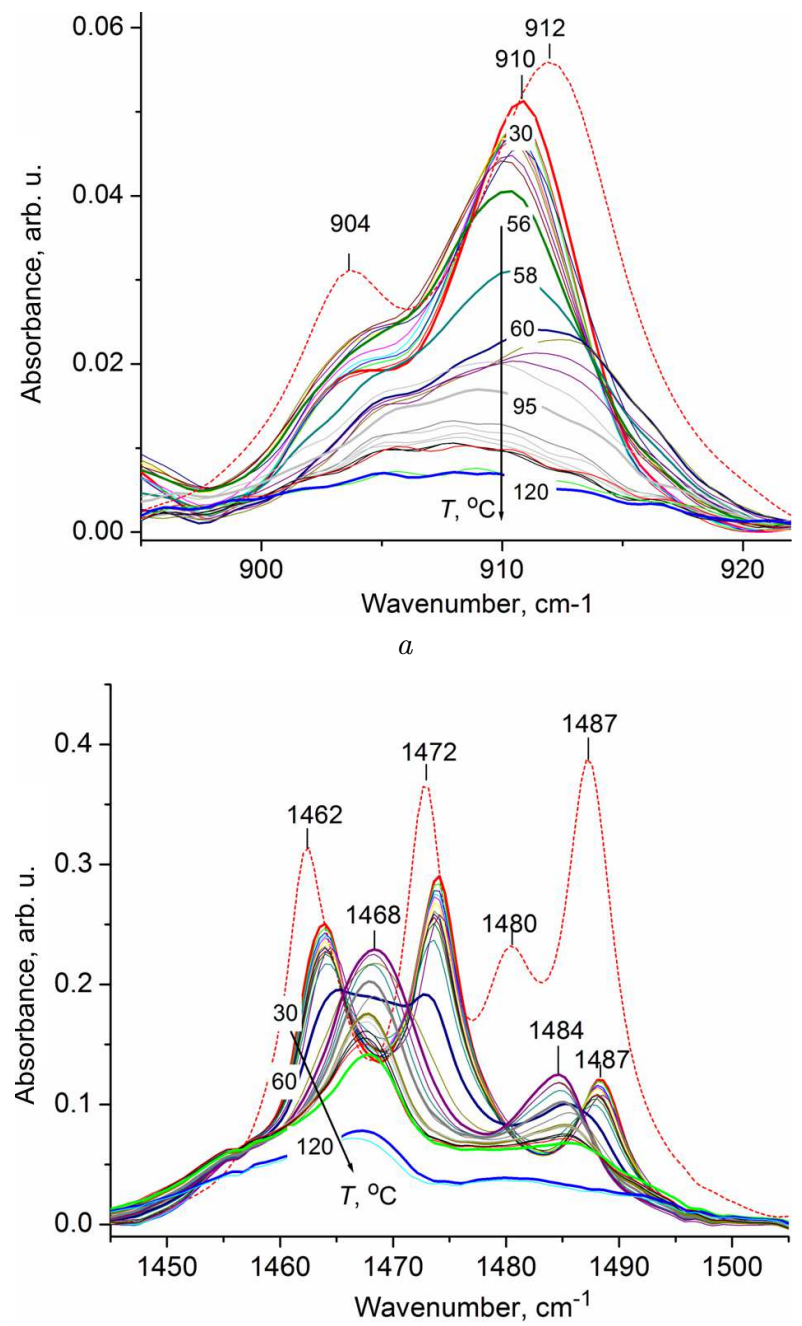

Fig. 8. Temperature evolution of the $\mathrm{C}-\mathrm{N}^{+}$stretching (a) and $\mathrm{N}^{+}-\left(\mathrm{CH}_{3}\right)(b)$ bending vibration bands in FTIR spectra of the $1: 1 \mathrm{kC} 12-\mathrm{CTAB}$ complex against the pristine roomtemperature CTAB (dotted line)

ing temperature, the single broad band is observed at $1468 \mathrm{~cm}^{-1}$ indicating a collapse of interchain interactions and an increase in the chain rotation, which is usually associated with the liquid state. The weakness of the $\delta_{\mathrm{as}}\left(\mathrm{N}^{+}-\mathrm{CH}_{3}\right)$ band centered at $1487 \mathrm{~cm}^{-1}$ supports the contention that since the $\mathrm{N}^{+}-\left(\mathrm{CH}_{3}\right)_{3}$ group in the complex is electrostatically bound to a $\mathrm{COO}^{-}$group, the modified head group structure occupies a larger volume, by giving more freedom to $\mathrm{CH}_{3}$ group molecular rotations in the crystalline phase. This may be a reason for the corresponding $\mathrm{N}^{+}-\left(\mathrm{CH}_{3}\right)_{3}$ stretching band in the crystalline com- 


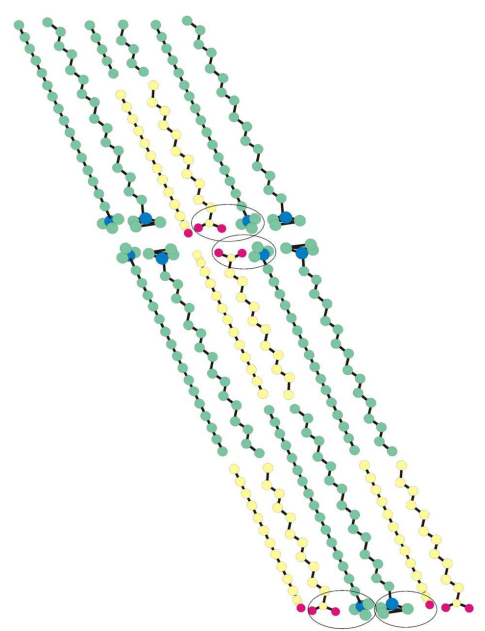

Fig. 9. Schematic representation of the molecular packing of the $1: 1 \mathrm{kC} 12$-CTAB binary complex in the crystalline state

plex to be shifted and broadened, as compared to that of pure CTAB due to the increased molecular motion.

Summarizing, the analysis of FTIR spectroscopy data for both the head group and alkyl chain vibrations of the complex shows that all changes that occur after the complex formation, as well as at the temperature-induced phase transitions related to the disordering or melting of the alkyl chain can be observed in the infrared spectra. The temperatures, at which all these transitions are observed, well match those obtained with the DSC method. The analysis of FTIR spectroscopic results suggests a cooperative mechanism of successive solid-state phase transitions in the complex that involves the "melting" of alkyl chains followed by a structural transition to the crystalline hexagonal phase with hindered rotation of the coupled kC12-CTAB moieties with the further melting of the electrostatically bonded complex.

\subsubsection{Discussion of the molecular packing in the solid kC12-CTAB complexes}

The analysis of data obtained from our XRD, DSC, and FTIR spectroscopy measurements allows us to suggest the following crystalline structure of the resulting binary complex. Let us consider the equimolar binary complex consisting of CTAB and $\mathrm{kC12}$ acid. According to XRD data, neither CTAB nor $\mathrm{kC1}$ molecules are arranged in their initial structure, but they are packed in a new way. The XRD pattern obtained for the complex indicates that it crystallizes in a bilayer structure with methylene chains tilted to the layer plane at an angle of about $70^{\circ}$. However, the XRD data do not give us the molecular arrangement in the bilayers. According to our DSC results, the first phase transition temperature in the complex increases by about $10 \mathrm{C}$, as compared to that of the pristine $\mathrm{kC12}$. This suggests that the $\mathrm{kC12}$ and CTAB moieties in the binary complex are not located separately in different layers (which will melt therefore separately), but are located nearby. In addition, the FTIR spectra reveal the Davydov splitting for $\mathrm{CH}_{2}$ rocking vibrations at the room-temperature spectra of the binary complex, while no such splitting was observed for the pristine $\mathrm{kC12}$. This observation confirms the orthorhombic structure of the binary complex with two translationally nonequivalent alkyl chains in Vand's subcell for both $\mathrm{kC} 12$ and CTAB moieties. Based on these results, we suggest the possible molecular structure for the complex that is shown in Fig. 9. We could assume also the similar structures for other previously studied 1:1 FA-CTAB complexes with different mismatches of alkyl chain lengths.

According to our model, both alkyl chains in the binary complex in the crystalline state are packed in a lamellar structure with orthorhombic Vand's subcell with two molecules, despite that the initial $\mathrm{kC12}$ has a triclinic crystal structure with one molecule per Vand's cell. It is the non-covalent binding interactions with CTAB molecules that are responsible for the observed changes in the packing of $\mathrm{kC} 12$ chains in the crystal structure of the complex.

\section{Conclusions}

For the first time, the equimolar solid-state binary complex of long-chain cationic and anionic surfactants comprising $\mathrm{kC12}$ lauric acid and $\mathrm{CTAB}$ is prepared. The crystal structure and the solid-liquid phase behavior of the prepared complex are investigated by means of X-ray diffraction, differential scanning calorimetry, and temperature-variable Fourier transform infrared spectroscopy. It is found that the complex crystallizes in a bilayer structure, which is held together by both electrostatic bonding in the head-group and hydrophobic interactions between the methylene chains. This is confirmed with the FTIR spectroscopy. The DSC study confirmed the formation of the binary complex with a melting point different from those of pure lauric acid and CTAB and with a number of successive phase transitions; the 
melting point of the complex corresponds to the solidsolid phase transition in pristine CTAB. With FTIR spectroscopy, it is shown that the observed phase behavior reflects the intermolecular interaction between the binary complex moieties. It is also revealed that, unlike the initial acid, the alkyl chains of $\mathrm{kC} 12$ moieties in the crystalline state of the binary complex are packed in the orthorhombic structure.

Using a temperature dependence of the Davydov splitting of methylene rocking modes, the changes in the packing of methylene chains in different phase states are revealed. The good correlation between the DSC and FTIR data suggests a cooperative mechanism of successive phase transitions in the complex that involves the conformational "melting" of alkyl chains followed by a structural transition from the orthorhombic to hexagonal phase with hindered rotation of coupled $\mathrm{kC12}$-CTAB moieties with the further melting of the electrostatically bonded complex.

1. P. Jokela, B. Jonsson, A. Khan. Phase equilibria of catanionic surfactant-water systems. J. Phys. Chem. 91, 13291 (1987).

2. E. Marques, A. Khan,M. Miguel, B. Lindman. Self-assembly in mixtures of a cationic and an anionic surfactant: The sodium dodecyl sulfate-didodecyldimethylammonium bromide-water system. J. Phys. Chem. 97, 4729 (1993).

3. P.A. Hassan, S.R. Raghavan, E.W. Kaler. Microstructural changes in SDS micelles induced by hydrotropic salt. Langmuir 18 (7), 2543 (2002).

4. N. Vlachy, A. Renoncourt, M. Drechsler, J.-M. Verbavatz, D. Touraud, W. Kunz. Blastulae aggregates: New intermediate structures in the micelle-to-vesicle transition of catanionic systems. J. Colloid and Interface Sci. 320 (1), 360 (2008).

5. E.W. Kaler, K.L. Herrington, K. Marthy, J.A. Zasadzink. Phase behavior and structures of mixtures of anionic and cationic surfactants. J. Phys. Chem. 96 (16), 6698 (1992).

6. N. Dew, T. Bramer, K. Edsman. Catanionic aggregates formed from drugs and lauric or capric acids enable prolonged release from gels. J. Colloid and Interface Sci. $\mathbf{3 2 3}$ (2), 386 (2008).

7. N. Hassan, J.M. Ruso, A. Piñeiro. Hydrogenated/fluorinated catanionic surfactants as potential templates for nanostructure design. Langmuir 27 (16), 9719 (2011).

8. D. Ramimoghadam, M.Z. Bin Hussein, Y.H. TaufiqYap. The effect of sodium dodecyl sulfate (SDS) and cetyltrimethylammonium bromide (CTAB) on the properties of $\mathrm{ZnO}$ synthesized by hydrothermal method. Int. J. Mol. Sci. 13 (10), 13275 (2012).

9. H.H. Mantsch, S.F. Weng, P.W. Yang, H.H. Eysel. Structure and thermotropic phase behavior of sodium and potassium carboxylate ionomers. J. Molec. Structure 324 (1-2), 133 (1994).
10. M. Antonietti. Surfactants for novel templating applications. Current Opin. Colloid Interf. Sci. 6 (3), 244(2001).

11. Organized Monolayers and Assemblies: Structure, Processes and Function. Edited by D. Mobius, R. Miller (Elsevier Science, 2002).

12. T.A. Gavrilko, V.I. Styopkin, T.V. Bezrodna, G.O. Puchkovska, J. Baran, M. Drozd. Molecular dynamics and phase transitions behavior of binary mixtures of fatty acids and cetyltrimethylammonium bromide as studied via davydov splitting of molecular vibrational modes. Ukr. J. Phys. $\mathbf{5 8}$ (7), 636 (2013).

13. J. Baran, M. Drozd, T.A. Gavrilko, V.I. Styopkin. Structure, molecular dynamics, and thermotropic properties of stearic acid-CTAB catanionic surfactants with different molar ratios. Ukr. J. Phys. 59 (3), 303 (2014).

14. E. von Sydow. On the structure of crystal form A of lauric acid. Acta Chem. Scand. 10 (1), 1 (1956).

15. V. Tomašic, S. Popovic, N. Filipovic-Vincekovic. Solid state transitions of asymmetric catanionic surfactants. J. Colloid and Interface Sci. 215 (2), 280 (1999).

16. M.L. Lynch, F. Wireko, M. Tarek, M. Klein. Intermolecular interactions and the structure of fatty acid-soap crystals. J. Phys. Chem. B 105 (2), 552 (2001).

17. N. Filipovic-Vincekovic, I. Pucic, S. Popovic, V. Tomašic, D. Težak. Solid-phase transitions of catanionic surfactants. J. Colloid and Interface Sci. 188 (2), 396 (1997).

18. K. Iwamoto, Y. Ohnuki, K. Sawada, M. Seno. Solid-solid phase transitions of long-chain n-alkyltrimethylammonium halides. Mol. Cryst. Liq. Cryst. 73 (1-2), 95 (1981).

19. G.D. Saraiva, C.E.S. Nogueira, P.T.C. Freire, F.F. Sousa, J.H. Silva, A.M.R. Teixeira, J. Mendes Filho. Temperature-dependent vibrational spectroscopic study and DFT calculations of the sorbic acid. Spectrochimica Acta Part A 137, 1409 (2015).

20. F.F. Sousa, P.T.C. Freire, A.S. Menezes, G.S. Pinheiro, L.P. Cardoso, Jr.P. Alcantara, S.G.C. Moreira, F.E.A. Melo, J. Mendes Filho, G.D. Saraiva. Low-temperature phase transformation studies in the stearic acid: $\mathrm{C}$ form. Spectrochimica Acta Part A 148 (9), 280 (2015).

21. R.G. Snyder, S.L. Hsu, S. Krimm. Vibrational spectra in the $\mathrm{CH}$ stretching region and the structure of the polymethylene chain. Spectrochimica Acta A 34 (4), 395(1978).

22. L.J. Bellami. The Infra-Red Spectra of Complex Molecules, Vol. 1 (Wiley, 1975).

23. G.O. Puchkovska. Manifestation of structure, dynamics, and polymorphism in vibrational spectra of molecular crystals. Thesis of the Doctoral Dissertation in Phys. and Math. (Kyiv, 1988).

24. G.O. Puchkovska, S.P. Makarenko, V.D. Danchuk, A.P. Kravchuk. Temperature study of resonance intermolecular interaction in normal long-chain carboxylic acid crystals using IR absorption spectra. J. Molec. Struct. 744-747, 53 (2005).

25. E.B. Sirota, H.E. King Jr., D.M. Singer, H.S. Shao. Rotator phases of the normal alkanes: An X-ray scattering study. J. Chem. Phys. 98 (7), 5809 (1993). 
26. C. Sun, M.J. Bojdys, S.M. Clarke, L.D. Harper, A. Jefferson, M.A. Castro, S. Medina. Bulk and adsorbed monolayer phase behavior of binary mixtures of undecanoic acid and undecylamine: Catanionic monolayers. Langmuir $\mathbf{2 7}$ (7), 3626 (2011).

Received 01.12.17

Т. Гаврилко, І. Гнатюк,

В. Стъопкін, Н. Щербанъ, Я.Баран, М. Дрозд

СПЕКТРОСКОПІЧНІ ТА КАЛОРИМЕТРИЧНІ

ДОСЛІДЖЕННЯ БІНАРНИХ СУМШШЕЙ

ДОВГОЛАНЦЮЖКОВИХ АЛІФАТИЧНИХ

СПОЛУК: ЛАУРИНОВА КИСЛОТА

ТА БРОМІД ЦЕТИЛТРИМЕТИЛАМОНІЮ

$\mathrm{P}$ е $з$ ю м е

Проведено комплексне дослідження структурних та термічних властивостей твердотільних бінарних сумішей довголанцюжкових катіонних і аніонних поверхнево-активних сполук (так званих катаніонних комплексів), що складаються з броміду цетилтриметиламмонію, $\left[\mathrm{H}_{3} \mathrm{C}\left(\mathrm{CH}_{2}\right)_{15}\right.$ $\left.\mathrm{N}^{+}\left(\mathrm{CH}_{3}\right)_{3}\right] \mathrm{Br}^{-}($ЦАБ), та насичених жирних кислот $(\mathrm{KK})$, зокрема $\mathrm{CH}_{3}\left(\mathrm{CH}_{2}\right)_{12} \mathrm{COOH}$ (лауринова кислота, $\mathrm{kC12}$ ). Для з'ясування впливу міжмолекулярної взаємодії на особливості кристалічної структури та фазових переходів у цьому класі супрамолекулярних сполук, в представленій роботі ми приділили особливу увагу дослідженню бінарної суміші $1: 1$ кС12-ЦТАБ за допомогою методів рентгенівської дифракції, диференціальної скануючої калориметрії (ДСК) та інфрачервоної спектроскопії з перетворенням Фур'є у широкому інтервалі температур (20-150 $\left.{ }^{\circ} \mathrm{C}\right)$. На підставі порівняння отриманих результатів 3 одержаними нами раніше для інших бінарних сумішей ЦТАБ $з$ ЖК з більш довгими алкільними ланцюжками, запропоновано можливу молекулярну упаковку в кристалічній структурі комплексів ЖКК-ЦАБ та встановлено механізм послідовних фазових переходів у конденсованому стані таких сполук. 